\title{
Exposure to dolutegravir in pregnant women living with HIV in Central and Eastern Europe and neighboring countries - data from the ECEE Network Group
}

\author{
Deniz Gokengin ${ }^{1}$, Inka Aho² ${ }^{2}$ Figen Sarıgül Yıldırım³ ${ }^{3}$, Pavla Bukovinova4 ${ }^{4}$ Ewa Siwak ${ }^{5}$, \\ Antonios Papadopoulos ${ }^{6}$, Dalibor Sedlacek ${ }^{7}$, Justyna Kowalska ${ }^{5,8}$ \\ ${ }^{1}$ Ege University Faculty of Medicine Department of Infectious Diseases, Izmir, Turkey \\ ${ }^{2}$ Helsinki University Hospital, Helsinki, Finland \\ ${ }^{3}$ Health Science University Antalya Education and Training Hospital, Antalya, Turkey \\ ${ }^{4}$ Department of Infectious Diseases and Geographical Medicine UH, Bratislava, Slovakia \\ ${ }^{5}$ Hospital for Infectious Diseases, HIV Out-Patient Clinic, Warsaw, Poland \\ ${ }^{6}$ University Hospital, Athens, Greece \\ ${ }^{7}$ HIV Centre, Department of Infectious Diseases, University Hospital, Plzen, Czech Republic \\ ${ }^{8}$ Medical University of Warsaw, Department of Adult's Infectious Diseases, Warsaw, Poland
}

\begin{abstract}
Objectives: The purpose of this study was to investigate dolutegravir (DTG) use among women and exposure to DTG during pregnancy in real world in Central and Eastern Europe and neighboring countries.

Material and methods: Centres from 20 countries included in the Euroguidelines in Central and Eastern Europe (ECEE) Network and Finland were asked to complete an on-line questionnaire.

Results: Seven centres from Czech Republic, Finland, Greece, Poland, Slovakia, and Turkey provided detailed information. DTG exposure was reported in 415 women, of which 26 were during pregnancy. Of those, 22 were on DTG at the time of conception and 4 had started DTG during pregnancy. Few women had conventional risk factors. The data on folic acid usage was unknown for eight women; 14 were using and four were not using folic acid. Four pregnancies were ongoing at the time of the study and of those with an outcome, $77.3 \%$ resulted with term, $13.6 \%$ preterm delivery, $4.5 \%$ spontaneous and $4.5 \%$ medical abortion.

Conclusions: The DTG signal report indicates the importance of safety research for drug use in pregnancy and highlights the urgent need for systematic surveillance of pregnancy outcomes and neonatal surveillance. Countries with low- or moderate HIV prevalence should be included in studies reviewing pregnancy outcomes and in any surveillance system to ensure the accuracy of drug safety revision.
\end{abstract}

Key words: HIV infection; dolutegravir; pregnancy; Central and Eastern Europe

Ginekologia Polska 2019; 90, 7: 411-415

\section{INTRODUCTION}

Integrase strand transfer inhibitors (InSTIs) have become the mainstay of antiretroviral treatment (ART) recently owing to their high virologic activity, durability, minimized drug-drug interactions, low adverse event profile, and tolerability [1]. They are recommended as first-line antiretroviral drugs to be included in the treatment regimens of ART-naive patients in major guidelines [2, 3] and becoming more widely accessible across national guidelines in the Sentral and Eastern European (CEE) region [4]. Dolutegravir (DTG) has been studied extensively among adults and children living with HIV and has replaced efavirenz (EFV) in the latest updated World Health Organization (WHO) guidelines [3]. However, the interim analysis of the Tsepamo study comparing DTG with EFV revealed a higher rate of neural tube defects (NTDs) in infants born to mothers using DTG at conception compared 
to those using EFV or non-DTG-containing regimens [5]. This unexpected finding resulted in safety warnings for the use of DTG in pregnant women and women of childbearing age, which restricted its use significantly [6]. It is estimated that restricting DTG use may compromise the overall benefit and access to modern combination ART for women living with HIV [7]. In order to balance the risks and benefits at the population level it is necessary to assess what the size of the population at risk is i.e. the number of women of childbearing age and the number of women conceiving on the drug.

\section{Objectives}

The aim of this study was therefore to investigate DTG use among women and exposure to DTG during pregnancy in real world in Central and Eastern Europe and neighboring countries where epidemiological data are few and HIV prevalence is low- or moderate-level.

\section{MATERIAL AND METHODS}

Centres from 20 countries included in the Euroguidelines in Central and Eastern Europe (ECEE) Network along with Finland were approached in June 2018 and were asked to complete an on-line questionnaire about DTG availability, the scale of its use among women, and exposure to DTG during pregnancy (Tab. 1). DTG was available in twelve centres, and eight centres reported use of DTG in pregnant women. Seven centres from six countries (Czech Republic, Finland, Greece, Poland, Slovakia, and Turkey) provided detailed information on the use of DTG during pregnancy, and data on other risk factors. Follow-up was censored at 31 July, 2018.

\section{RESULTS}

A total of 415 women were exposed to DTG in seven centres and 26 were exposed during pregnancy. Of those, 22 were on DTG at the time of conception and 4 had started DTG during pregnancy. In only one patient who conceived a month before the warning for DTG use in pregnancy was released, the ART regimen was switched to darunavir/ritonavir + raltegravir (RAL). The remaining patients stayed on DTG.

Few women had conventional risk factors. Only one woman continued to use psychoactive substances and alcohol during pregnancy. Two women stopped psychoactive drugs and one alcohol after they became pregnant. Four were smokers at the time of conception; two of those stopped after being pregnant.

The status of acute or reactive TORCH diseases was available for 23 women and for all it was negative. Hepatitis $C$ antibodies were negative for 23 women, two had positive antibodies with confirmed HCV RNA positivity, and one had positive antibodies but an unknown RNA status.

Other concomitant illnesses included three hypothyreosis, one autoimmune hepatitis, one insulin-dependent diabe- tes, and one systemic lupus erythematosus. One woman had gestational diabetes stage $A$ and one Rh incompatibility.

The data on folic acid usage was unknown for eight women, 14 were using and four were not using folic acid.

The median number of prior pregnancies was one [interquartile range (IQR): 0-3]. Six had a prior caesarian section (CS), six were reported to have an induced abortion, and four a spontaneous abortion when HIV positive.

Four pregnancies were ongoing at the time of the study. Of the 22 pregnancies with an outcome, there were 17 (77.3\%) term deliveries, three (13.6\%) preterm deliveries, one (4.5\%) spontaneous and one (4.5\%) medical abortion.

\section{DISCUSSION}

This study is the first to report on DTG use among women and during pregnancy in ECEE Network countries showing that a substantial number of women were exposed to DTG in the region. The introduction of InSTIs to the market in Central and Eastern Europe, especially in low and lower-middle income countries was delayed. In our study only 12 out of 20 centres had access to the drug, all of which are high-income or upper-middle income countries. There seems to be no improvement over time, as similarly in a study from 2015 including 24 countries from the Eastern and Central Europe, DTG was available in half, RAL in 70\%, and elvitegravir fixed-dose combination only in $20 \%$ and again the majority (75\%) was high or upper-middle income countries [8]. The relatively high number of women exposed to DTG in our study, is an indicator that DTG has become a preferable antiretroviral drug in the region.

Initially a few small cohorts from Europe and North America and a larger series from Botswana (the Tsepamo study) reported no evidence of increased birth defects in infants born to mothers who conceived while using DTG [9-13]. However, in April 2018, an unplanned interim analysis requested by the WHO of the Tsepamo-cohort revealed an unexpectedly higher rate of NTDs among infants born to mothers who conceived on DTG compared to those using non-DTG regimens ( $0.94 \%$ and $0.12 \%$, respectively) [5].

This unexpected finding resulted with a warning message from the European Medicines Agency (EMA) and the WHO for designing ART regimens for women of reproductive age and pregnant women based on drugs with reliable efficacy and safety data such as an efavirenz-based regimen. $[6,14]$. Similarly, all major guidelines issued new recommendations regarding DTG use in women of childbearing age and in pregnant women [2].

In African countries the warnings on DTG resulted in almost immediate banning of the drug use among women of reproductive age [15]. Shutting off access to a superior regimen without extensive discussions with the relevant party was considered unacceptable and was widely criticized by 
Table 1. Questionnaire used for data collection

\begin{tabular}{|c|c|c|}
\hline Question & Response choice & Open ended question \\
\hline Number of women on DTG in your centre: & Number & $\mathrm{n} / \mathrm{a}$ \\
\hline Number of women who got pregnant while being on DTG: & Number & $\mathrm{n} / \mathrm{a}$ \\
\hline Number of women who started DTG during pregnancy: & Number & $\mathrm{n} / \mathrm{a}$ \\
\hline Date of starting DTG: & Date/Time & \\
\hline If DTG was switched provide date of stopping DTG: & Date/Time & \\
\hline If DTG was switched provide name of new ARVs: & Text & Yes \\
\hline NNRTI used in this pregnancy: & Text & Yes \\
\hline Concurrent use of other medication (not ARV): & Yes (please specify)/no/unknown & Yes \\
\hline Concurrent use of folic acid: & Yes (please specify)/no/unknown & Yes \\
\hline Any health problems during pregnancy: & Yes (please specify)/no/unknown & Yes \\
\hline \multirow[t]{4}{*}{ HCV status: } & HCV antibodies negative & No \\
\hline & HCV antibodies positive & \\
\hline & HCV antibodies positive confirmed with HCV RNA & \\
\hline & HCV antibodies positive but HCV RNA not performed & \\
\hline Date of pregnancy start: & Date/Time & $\mathrm{n} / \mathrm{a}$ \\
\hline Number of pregnancies: & Number & $\mathrm{n} / \mathrm{a}$ \\
\hline Outcome of past pregnancies (please describe): & Text & Yes \\
\hline \multirow[t]{4}{*}{ Outcome of pregnancy exposed to DTG: } & Term delivery & Yes \\
\hline & Preterm delivery (<37 gestation week) & \\
\hline & Abortion & \\
\hline & Other (please describe) & \\
\hline Newborn outcome: & Text & Yes \\
\hline \multirow[t]{3}{*}{ Smoking: } & Yes and continued in pregnancy & No \\
\hline & Yes, but stopped at the begining of pregnancy & \\
\hline & No & \\
\hline \multirow[t]{3}{*}{ Alcohol: } & Yes and continued in pregnancy & No \\
\hline & Yes, but stopped at the begining of pregnancy & \\
\hline & No & \\
\hline \multirow[t]{3}{*}{ Psychoactive substance use: } & Yes and continued in pregnancy & No \\
\hline & Yes, but stopped at the begining of pregnancy & \\
\hline & No & \\
\hline TORCH diseases: & Yes (please specify)/no/unknown & Yes \\
\hline Date of delivery: & Date/Time & $\mathrm{n} / \mathrm{a}$ \\
\hline If not yet delivered - date of expected delivery: & Date/Time & $\mathrm{n} / \mathrm{a}$ \\
\hline
\end{tabular}

ARV — antiretroviral; DTG — dolutegravir; HCV — hepatitis C virus; NNRTI — non-nucleoside reverse transcriptase inhibitor; RNA — ribonucleic acid; TORCH - toxoplasma-other-rubella-cytomegalovirus-herpes

women's organizations in Africa [15]. A modelling study to compare various scenarios of ART policy in a hypothetical southern African population showed that the benefits of DTG should not be sacrificed for the potential risk of NTDs in a woman who has not conceived yet [7]. Although the HIV epidemic in ECEE Network is concerning in terms of women, the implications of such an approach has not been discussed for this region. Most of the Central and Eastern European region has experienced a low- or moderate-level epidemic and thus has not received enough attention for many years $[4,16]$. However, in many of those countries the epidemic is rapidly rising and mother-to-child transmission is still of concern [17]. DTG-based therapy proved to be effective in achieving rapid viral suppression in pregnant women, even in late presenters and those with highly resistant virus, and in preventing mother-to-child transmission. This makes it an attractive choice in many settings including pregnancy $[12,18-21]$. DTG is becoming a preferred antiretroviral drug in the region and reliable data are required urgently for such settings. 
In the general population NTDs were responsible for the highest disability and mortality rate among all birth defects. Although the etiology of NTDs is not clear yet several factors such as genetics, nutrition, and environmental factors were suggested. Two randomized controlled studies and several observational studies showed that NTDs were prevented by $50 \%$ if women consumed a folic acid-containing supplement before and during early pregnancy [22, 23]. An important finding in our study was that almost half of the women who conceived on DTG were either not using folic acid or had no available data on its use, which seems like a significant gap in prevention of NTDs. In addition to folic acid depletion, obesity, poor control of diabetes mellitus, and use of some anti-epileptic drugs were also associated with a higher risk of spina bifida or anencephaly in the infant [24-28]. In our study concomitant illnesses reported among pregnant women exposed to DTG were three hypothyreosis, one autoimmune hepatitis, one insulin-dependent diabetes, and one systemic lupus erythematosus. One woman had gestational diabetes stage $A$ and one Rh incompatibility. We would like therefore to highlight the importance of complete assessment of medical history in women exposed to antiviral drugs in pregnancy. Neglecting to collect and analyze these data may result in overestimating the toxicity related to antiretroviral drugs and undermining women's rights to best possible standard of care [29]. The latest results of the Tsepamo study from Botswana suggest that although lower than the previous rate $(0.67 \%)$, the increased risk still remains. On the other hand, these findings were not yet replicated either by case series, observational cohorts or joined pregnancy surveillance reports [12,30-33]. Therefore, the current scene is that the controversy has not resolved yet.

The DTG story indicates the importance of safety research for drug use in pregnancy. Moreover, it highlights the urgent need for systematic surveillance of pregnancy outcomes and neonatal surveillance. Mechanisms ensuring such reporting with necessary quality, e.g. excluding double reporting, are necessary to ascertain prolonged benefit from ART irrespective of gender [34]. Another subject of discussion was that in order to refute an NTD signal a large number of preconception exposures would be required. As estimated by Schomaker et al [35] if one new defect would be reported we would need 2000 exposures to see a lower confidence interval to overlap non-DTG prevalence. Therefore countries with low- or moderate HIV prevalence should be included in studies reviewing pregnancy outcomes as well as in any surviellance system in order to ascertain the completeness of drug safety revision.

\section{Conflict of interests}

On behalf of all authors, the corresponding author states that there is no conflict of interests.

\section{REFERENCES}

1. Messiaen P, Wensing AMJ, Fun A, et al. Clinical use of HIV integrase inhibitors: a systematic review and meta-analysis. PLoS One. 2013; 8(1): e52562, doi: 10.1371/journal.pone.0052562, indexed in Pubmed: 23341902.

2. European AIDS Clinical Society Guidelines. Version 9.1. October 2018. Clinical Society Guidelines. Version 9.1. October 2018. http://www. eacsociety.org/files/2018_guidelines-9.1-english.pdf. (11.03.2019).

3. Updated recommendations on first-line and second-line antiretroviral regimens and post-exposure prophylaxis and recommendations on early infant diagnosis of HIV: interim guidelines. Supplement to the 2016 consolidated guidelines on the use of antiretroviral drugs for treating and preventing HIV infection (WHO/CDS/HIV/18.51). Geneva: World Health Organization, 2018.

4. Kowalska JD, Oprea C, de Witt S, et al. ECEE Network Group. Euroguidelines in Central and Eastern Europe (ECEE) conference and the Warsaw Declaration - a comprehensive meeting report. HIV Med. 2017; 18(5): 370-375, doi: 10.1111/hiv.12436, indexed in Pubmed: 27553526.

5. Zash R, Makhema J, Shapiro RL. Neural-Tube Defects with Dolutegravir Treatment from the Time of Conception. N Engl J Med. 2018; 379(10): 979-981, doi: 10.1056/NEJMc1807653, indexed in Pubmed: 30037297.

6. WHO Statement on Dolutegravir. Geneva18 May 2018. WHO Statement on Dolutegravir. Geneva18 May 2018. https://www.who.int/medicines/publications/drugalerts/Statement_on_DTG_18May_2018final. pdf. (11.03.2019).

7. Phillips AN, Venter F, Havlir D, et al. Risks and benefits of dolutegravir-based antiretroviral drug regimens in sub-Saharan Africa: a modelling study. Lancet HIV. 2019; 6(2): e116-e127, doi: 10.1016/S23523018(18)30317-5, indexed in Pubmed: 30503325.

8. Gokengin D, Oprea C, Begovac J, et al. HIV care in Central and Eastern Europe: How close are we to the target? Int J Infect Dis. 2018; 70: 121-130, doi: 10.1016/j.ijid.2018.03.007, indexed in Pubmed: 29550449.

9. Thorne $\mathrm{C}$, Favarato $\mathrm{G}$, Peters $\mathrm{H}$, et al. Pregnancy and neonatal outcomes following prenatal exposure to dolutegravir. 9th IAS Conference on HIV Science; Paris, France; July 23-26. 2017: Abstract 4549.

10. Vannappagari V, Albano J, Ragone L, et al. Dolutegravir use during pregnancy and birth outcomes: data from the Antiretroviral Pregnancy Registry (APR). 9th IAS Conference on HIV Science. Paris, France; July 23-26. 2017: Abstract 68.

11. Vitoria $\mathrm{M}$, Ford $\mathrm{N}$, Clayden $\mathrm{P}$, et al. When could new antiretrovirals be recommended for national treatment programmes in low-income and middle-income countries: results of a WHO Think Tank. Curr Opin HIV AIDS. 2017; 12(4): 414-422, doi: 10.1097/COH.0000000000000380, indexed in Pubmed: 28410249.

12. Bornhede R, Soeria-Atmadja S, Westling $K$, et al. Dolutegravir in pregnancy-effects on HIV-positive women and their infants. Eur J Clin Microbiol Infect Dis. 2018; 37(3): 495-500, doi: 10.1007/s10096-0183195-9, indexed in Pubmed: 29396773.

13. Zash R, Jacobson DL, Diseko M, et al. Comparative safety of dolutegravir-based or efavirenz-based antiretroviral treatment started during pregnancy in Botswana: an observational study. Lancet Glob Health. 2018; 6(7): e804-e810, doi: 10.1016/S2214-109X(18)30218-3, indexed in Pubmed: 29880310.

14. New study suggests risk of birth defects in babies born to women on HIV medicine dolutegravir. European Medicines Agency Press Release 18.05.2018. New study suggests risk of birth defects in babies born to women on HIV medicine dolutegravir. European Medicines Agency Press Release 18.05.2018. https://www.ema.europa. eu/en/news/new-study-suggests-risk-birth-defects-babies-born-women-hiv-medicine-dolutegravir..

15. Nakkazi E. Changes to dolutegravir policy in several African countries. Lancet. 2018;392(10143): 199, doi: 10.1016/S0140-6736(18)31641-6, indexed in Pubmed: 30043745.

16. Balayan T, Oprea C, Yurin O, et al. Euro-guidelines in Central and Eastern Europe Network Group. People who inject drugs remain hard-to-reach population across all HIV continuum stages in Central, Eastern and South Eastern Europe - data from Euro-guidelines in Central and Eastern Europe Network. Infect Dis (Lond). 2019; 51(4): 277-286, doi: 10.1080/23744235.2019.1565415, indexed in Pubmed: 30786803.

17. Thorne C, Semenenko I, PilipenkoT, et al. Ukraine European Collaborative Study Group. Progress in prevention of mother-to-child transmission of HIV infection in Ukraine: results from a birth cohort study. BMC Infect Dis. 2009; 9: 40, doi: 10.1186/1471-2334-9-40, indexed in Pubmed: 19351387. 
18. Rahangdale L, Cates J, Potter J, et al. HOPES (HIV OB Pregnancy Education Study) Group. Integrase inhibitors in late pregnancy and rapid HIV viral load reduction. Am J Obstet Gynecol. 2016; 214(3): 385.e1-385.e7, doi: 10.1016/j.ajog.2015.12.052, indexed in Pubmed: 26928154.

19. Mulligan N, Best BM, Wang J, et al. IMPAACT P1026s Protocol Team. Dolutegravir pharmacokinetics in pregnant and postpartum women living with HIV. AIDS. 2018; 32(6): 729-737, doi: 10.1097/QAD.0000000000001755, indexed in Pubmed: 29369162.

20. Grayhack C, Sheth A, Kirby O, et al. Evaluating outcomes of mother-infant pairs using dolutegravir for HIV treatment during pregnancy. AIDS. 2018; 32(14): 2017-2021, doi: 10.1097/QAD.0000000000001931, indexed in Pubmed: 29944472.

21. Mounce ML, Pontiggia L, Adams JL. A Single-Center Retrospective Cohort Analysis of Maternal and Infant Outcomes in HIV-Infected Mothers Treated with Integrase Inhibitors During Pregnancy. Infect Dis Ther. 2017; 6(4): 531-544, doi: 10.1007/s40121-017-0170-1, indexed in Pubmed: 28905222.

22. Prevention of neural tube defects: results of the Medical Research Council Vitamin Study. MRC Vitamin Study Research Group. Lancet. 1991; 338(8760): 131-137, indexed in Pubmed: 1677062.

23. Czeizel AE, Dudás I. Prevention of the first occurrence of neural-tube defects by periconceptional vitamin supplementation. N Engl J Med. 1992; 327(26): 1832-1835, doi: 10.1056/NEJM199212243272602, indexed in Pubmed: 1307234.

24. Kantola-Sorsa E, Gaily E, Isoaho M, et al. Neuropsychological outcomes in children of mothers with epilepsy. J Int Neuropsychol Soc. 2007; 13(4):642652, doi: 10.1017/S1355617707070804, indexed in Pubmed: 17521493.

25. Meador KJ, Baker GA, Finnell RH, et al. NEAD Study Group. In utero antiepileptic drug exposure: fetal death and malformations. Neurology. 2006; 67(3): 407-412, doi: 10.1212/01.wnl.0000227919.81208.b2, indexed in Pubmed: 16894099.

26. Martínez-Frías ML. Epidemiological analysis of outcomes of pregnancy in diabetic mothers: identification of the most characteristic and most frequent congenital anomalies. Am J Med Genet. 1994; 51(2): 108-113, doi: 10.1002/ajmg.1320510206, indexed in Pubmed: 8092185.
27. Martínez-Frías ML, Bermejo E, Rodríguez-Pinilla E, et al. Epidemiological analysis of outcomes of pregnancy in gestational diabetic mothers. Am J Med Genet. 1998; 78(2): 140-145, indexed in Pubmed: 9674904.

28. McMahon DM, Liu J, Zhang $\mathrm{H}$, et al. Maternal obesity, folate intake, and neural tube defects in offspring. Birth Defects Res A Clin Mol Teratol. 2013; 97(2): 115-122, doi: 10.1002/bdra.23113, indexed in Pubmed: 23404872.

29. Kowalska JD, Aebi-Popp K, Loutfy M, et al. Women Against Viruses in Europe (WAVE) Working Group. Promoting high standards of care for women living with HIV: position statement from the Women Against Viruses in Europe Working Group. HIV Med. 2018; 19(2): 167-173, doi: 10.1111/hiv.12565, indexed in Pubmed: 29159861.

30. Weissmann D, De Le, Gute $P$, et al. Use of integrase inhibitors in HIV-positive pregnant women: data from the Frankfurt HIV cohort. HIV Drug Therapy. ; 2018: P002.

31. Sibiude J, Le Ch, Mandelbrot $L$, et al. No increase in birth defects in infants exposed to integrase inhibitors at conception. Conference on Retroviruses and Opportunistic Infections. March 4-7 2019, Seattle, USA. : Abstract no. 744.

32. Hill A, van de, Pozniak A, et al. et al.. Reports of neural tube defects for 8 ARTs, , WHO, EMA, and UK safety databases. Conference on Retroviruses and Opportunistic Infections. March 4-7 2019, Seattle, USA. : Abstract no. 746.

33. Albano JD, Vannappagari V, Scheuerle A, et al. InSTlexposure and neural tube defects: data from antiretroviral pregnancy registry. Conference on Retroviruses and Opportunistic Infections. March 4-7 2019, Seattle, USA. : Abstract no. 747.

34. Dolutegravir for HIV: a lesson in pregnancy safety research. Lancet. 2018; 391(10137): 2296, doi: 10.1016/S0140-6736(18)31265-0, indexed in Pubmed: 29900859.

35. Schomaker M, Davies MA, Cornell M, et al. Assessing the risk of dolutegravir for women of childbearing potential. Lancet Glob Health. 2018; 6(9): e958-e959, doi: 10.1016/S2214-109X(18)30326-7, indexed in Pubmed: 30049617. 